years, and particularly since 1931, Prof. Wright has developed the modern mathematical theory of biological evolution. In the past, different authors attributed the principal role in evolution to different factors; there existed partisans of natural selection, of mutation, of hybridization, etc. Wright has shown that what is most important is the quantitative interrelations of all the factors. $\mathrm{He}$ has also discovered a new evolutionary agent, now known as the genetic drift or the Sewall Wright phenomenon. This hitherto almost unsuspected phenomenon is probably very effective, in connexion with the other previously known agents, in bringing about the theoretically most important and interesting form of evolutionary change, known as progressive evolution. The brilliant synthesis reached by Prof. Wright makes him the outstanding living evolutionist and the father of the modern neo-Darwinism.

The Public Welfare Medal for 1947 of the U.S. National Academy of Sciences has been presented to Karl Taylor Compton, president of the Massachusetts Institute of Technology, for his notable contributions of an original character to the science of physics, for his long and valuable career in the field of education and of university administration, and in recognition of his eminent service in the war-time research effort of the American nation, and in the reinforcing of collaboration and understanding between civilian scientific workers and military men. In his presentation address, Dr. A. R. Dochez pointed out that the Marcellus Hartley Fund was established and placed at the disposal of the National Academy of Sciences for the purpose of giving conspicuous recognition to eminence in the application of science to the public welfare. From the inception of the National Defense Research Committee, when the hazard of possible war emergency demanded a major effort by the United States, through the years of the emergency, to the final successful conclusion of hostilities, both as a physicist and as an administrator, Dr. Compton made outstanding contributions. As chief of the Office of Field Service of the Office of Scientific Research and Development, he headed a unique and eminently effective effort at partnership between military and civilian experts in bringing to bear the full strength of science and technology in the defence of the American way of life.

\section{Research in Surveying at University College, London}

THE institution in 1946 in the Department of Civil Engineering at University College, London, of the first chair in surveying and photogrammetry in the United Kingdom, to which Dr. C. A. Hart was appointed, has excited considerable interest in the Commonwealth and overseas. This has been par. ticularly so because of recent advances in air survey and of the increasing employment of radar tech. niques both for air survey and geodetic surveying. At University College funds have been made available for the provision of first-class teaching and research equipment in surveying, with particular reference to photogrammetry. Emphasis on surveying in the Civil Engineering and Geography Schools has long been a feature at the College, and it is now proposed to institute a one-year special course of a postgraduate character in surveying, commencing in October 1948. This course will be arranged so as to provide a training ground for those who wish to enter the Colonial Survey Service or take up other carzers of a similar character.

\section{Colonial Geological Survey Service}

AN important part of a comprehensive plan for the economic development of the British Colonies is a thorough investigation of their mineral resources. This involves a considerable expansion of the Colonial geological surveys and the completion of maps on reconnaissance and more detailed scales with the view to discovery of mineral deposits and the determination of their economic significance. Such a programme of investigation offers geologists a wide range of interest-scientific and economic-with the added attraction of pursuing field-work under varied geographical and climatic conditions. There is place, too, for those who wish to specialize in petrology, mineralogy, economic geology, geophysics, etc. Most Colonial geological surveys offer opportunities for research, and men are encouraged to do new work and prepare for research degrees. Wherever possible they are given facilities also to study special subjects related to their work. A considerable number of geologists will be required during the next four years and a slightly lesser number in succeeding years to carry out such a programme. The vacancies in view are announced so far as possible in advance so that men who desire an active life of field-work may be encouraged to pursue geological studies with reasonable prospect of securing an appointment in the Colonial Geological Survey Service. The vacancies anticipated during the next few years are as follows : 1948-52, an average of 25 a year; 1953-56, an average of 15 a year. The Colonies in which these vacancies will occur include the following: Kenya, Uganda, Tanganyika Territory, Northern Rhodesia, Nyasaland, Bechuanaland, Swaziland, Nigeria, Gold Coast, Sierra Leone, British Guiana, British Honduras, Malaya, North Borneo, Sarawak, and certain other smaller Colonies. The posts offered are, in general, permanent and pensionable in themselves, or such as to lead to permanent and pensionable posts; temporary service would ordinarily count for pension where there has been no break in service. The qualification required is a good honours degree in geology, preferably supplemented by a research degree. or research experience. Forms of application for appointment to the Colonial Geological Survey Service are obtainable on request from the Director of Recruitment (Colonial Service), Colonial Office, 15 Victoria Street, London, S.W.1.

\section{A Standard for Quality Control}

AN increasing number of British Standards refer to quality control in acceptance clauses, and B.S. 1313 : 1947 has been prepared to meet the need for a publication which would describe the simplest method of quality control, by the examination of the fraction defective in samples. It sets out accepted methods which are easy to use and which may safely and profitably replace 100 per cent routine examinations. They are widely applicable, and the publication, without dealing with the statistical principles underlying the methods, attempts to show how to use them. Simple instructions are given for the construction and use of a quality control chart in the first section. The second section deals with the methods in more detail, describing the basis of fraction-defective charts, with detailed recommendations for sample size and interval, and normal control limits. Refinements in the general method are indicated in the third section, such as the uses of average level of defectives, two-way control charts 